Pesq. Vet. Bras. 30(5):465-469, maio 2010

\title{
Detecção do Grupo Mycoplasma mycoides por imunoperoxidase indireta (IPI) e PCR-REA em conduto auditivo de bovinos ${ }^{1}$
}

\author{
Sandra Batista dos Santos ${ }^{2}$, Elmiro Rosendo do Nascimento ${ }^{3^{*}}$, João Luiz \\ Horacio Faccini ${ }^{4}$, Maria Lúcia Barreto ${ }^{5}$, Juliana Ferreira de Almeida ${ }^{3}$, Virginia \\ Léo de Almeida Pereira ${ }^{3}$ e Carlos Augusto Martino Campos $^{5}$
}

\begin{abstract}
Santos S.B., Nascimento E.R., Faccini J.L.H., Barreto M.L., Almeida J.F., Pereira V.L.A. \& Campos C.A.M. 2010. [Detection of Mycoplasma mycoides cluster by indirect immunoperoxidase (IPI) and PCR-REA in the ear canal of bovines.] Detecção do Grupo Mycoplasma mycoides por imunoperoxidase indireta (IPI) e PCR-REA em conduto auditivo de bovinos. Pesquisa Veterinária Brasileira 30(5):465-469. Departamento de Saúde Coletiva Veterinária e Saúde Pública, Universidade Federal Fluminense, Rua Vital Brazil Filho 64, Niterói, RJ 24230-340, Brazil. E-mail: elmiro@vm.uff.br

Mycoplasma mycoides cluster (MMC) was diagnosed by polimerase chain reactionrestriction endonuclease analysis (PCR-REA) and indirect immunoperoxidase (IPI), both, carried out in flushing from external ear canal, collected from bovine at slaughter time in the State of Rio de Janeiro, southeastern, Brazil. A total of 60 bovines were randomly selected. Sterile syringes $(60 \mathrm{~mL}$ ) loaded with buffer solution (PBS, $\mathrm{pH} 7.2$ ) were used for the ear canal flushing. The obtained samples were stored in glycerol (1:2) and frozen at $-20^{\circ} \mathrm{C}$ until use. These specimens were diluted up to $10^{-5}$, inoculated in liquid and solid modified Hayflick's media and incubated at $37^{\circ} \mathrm{C}$ for $2-3$ days. The plates were kept in a microaerophilia condition and examined every two days under a stereomicroscope for the presence of typical colonies "fried-egg". In this study, 35 strains selected in agreement with their biochemistry and physiologic proprieties, were used. From the 60 cultivated samples, $48(80.00 \%)$ were positive for Mycoplasma spp. Under IPI the prevalence obtained for MMC was $20.0 \%$ (12/60) while by PCR-REA it was $41.7 \%$ (25/60). The IPI typing of these isolates resulted in $58.3 \%(7 / 12)$ for M.mycoides mycoides LC and 41.7\% (5/12) for M. capricolum. PCR-REA for MMC was confirmed by the amplicon size of $785 \mathrm{bp}$, compatible with this group. The Kappa value for the association between these two tests was 0.14 ( $p>0.05)$. After restriction analysis with Alul in all MMC strains the fragments size obtained were of 81, 98, 186 and 236bp, but not of $370 \mathrm{bp}$ that is compatible with Mycoides mycoides mycoides SC of bovine type. The presence of mycoplasmas species in the ear canal of asymptomatic bovines represent a risk of subsequent propagation of Mycoplasma spp. among bovine herds in Brazil.
\end{abstract}

INDEX TERMS: Mycoplasma mycoides, flushing ear, cattle, PCR-REA diagnostic.

\footnotetext{
${ }^{1}$ Recebido em 21 de abril de 2009.

Aceito para publicação em 8 de abril de 2010.

2 Doutoranda do Curso de Pós-Graduação em Ciências Veterinária, Universidade Federal Rural do Rio de Janeiro (UFRRJ), Seropédica, RJ 23890-000, Brasil.

${ }^{3}$ Departamento de Saúde Coletiva Veterinária e Saúde Pública, Universidade Federal Fluminense (UFF), Rua Vital Brazil Filho 64, Niterói, RJ 24230-340, Brasil. *Autor para correspondência: elmiro@vm.uff.br

${ }^{4}$ Departamento de Parasitologia Animal, Instituto de Veterinária, UFRRJ, Seropédica, RJ. Bolsista CNPq.

${ }^{5}$ Departamento de Imunobiologia, UFF, Morro São João Batista s/n, Centro, Niterói, RJ 24210-130, Brasil.
}

RESUMO.- O Grupo Mycoplasma mycoides (GMM) foi diagnosticado por PCR-REA e imunoperoxidase indireta (IPI) em amostras de lavados de conduto auditivo de bovinos no Estado do Rio de Janeiro, Brasil. 60 bovinos foram selecionados aleatoriamente. As lavagens foram feitas com uso de seringas estéreis contendo um volume de $60 \mathrm{~mL}$ de solução salina tamponada (PBS pH 7.2). As amostras obtidas foram estocadas em glicerol (1:2) e congeladas a $20^{\circ} \mathrm{C}$ até uso. Estas amostras foram diluídas até $10^{-5} \mathrm{e}$ repicadas em meio Hayflick modificado, sólido e líquido, 
sendo incubados a $37^{\circ} \mathrm{C}$ por $48-72$ horas. As placas foram mantidas em microaerofilia e observadas diariamente, para visualização das colônias típicas em "ovo-frito". Das 60 amostras cultivadas, $48(80,00 \%)$ foram positivas para Mycoplasma spp. A prevalência obtida para o GMM na IPI foi de $20,0 \%$ (12/60) enquanto na PCR-REA foi de $41,7 \%$ (25/60). Das cepas tipificadas pela IPI 58,3\% (7/12) foram M. mycoides subsp. mycoides LC e 41,7\% (5/12) foram M. capricolum. Na PCR-REA o grupo M. mycoides foi confirmado pela visualização de um amplicon de $785 \mathrm{bp}$, compatível com este grupo. O valor encontrado no teste Kappa para associação entre estes testes foi de 0,14 ( $P>0,05$. Na clivagem do produto da PCR com a enzima de restrição Alul, de cepas de referências e dos isolados de ouvido os fragmentos obtidos foram de $81,98,186$ e $236 \mathrm{pb}$, mas não de $370 \mathrm{pb}$, que é específica para o agente da Pleuropneumonia Contagiosa Bovina. A presença de espécies de micoplasmas no conduto auditivo de bovinos assintomáticos representa um risco para propagação de $\mathrm{Myco-}$ plasma spp. entre rebanhos bovinos no Brasil.

TERMOS DE INDEXAÇÃO: Grupo Mycoplasma mycoides, lavados de conduto auditivo, bovinos, diagnóstico por PCR-REA.

\section{INTRODUÇÃO}

Micoplasmas são bactérias pertencentes à Classe Mollicutes, cuja característica fenotípica mais importante é a ausência de parede celular. E apresentam estreita relação com bactérias Gram positivas (Pettersson et al. 1996 ,b, Razin et al. 1998). O Grupo Mycoplasma mycoides (GMM) constitui-se de seis espécies de micoplasmas estreitamente relacionadas em suas características bioquímicas e sorológicas e na filogenia do gene 16SrRNA. Estas semelhanças genéticas e fenotípicas do grupo causam problemas taxonômicos que dificultam o diagnóstico laboratorial, principalmente quando não se dispõe de técnicas moleculares (OIE 2008). As espécies agrupadas no GMM são conhecidas por provocar uma série de doenças em bovinos, caprinos e ovinos (OIE 2008). As espécies e subespécies que constituem o GMM são $M$. mycoides subsp. mycoides tipo SC (MmmSC), M. mycoides subsp. mycoides tipo LC (MmmLC), M. mycoides subsp. capri (Mmc), M. capricolum subsp. capricolum (Mcc), M. capricolum subsp. capripneumoniae (Mccp) e M. bovine Sorogrupo 7 (Msp7-PG50). As subespécies do Grupo da Pleuropneumonia Contagiosa Bovina (CBPP) e do Grupo da Pleuropneumonia Caprina (CCPP) são as mais estudadas neste grupo, devido a sua importância econômica em diversos países da África, da Ásia e da Europa.

A CBPP é uma das mais sérias doenças bacterianas de bovinos, tem como agente etiológico $M$. mycoides subsp. mycoides tipo SC (MmmSC). Na África, a CBPP causa grandes perdas econômicas para bovinocultura, e está amplamente difundida nas áreas tropicais e nas regiões leste e sudeste, com mortalidades que variam em torno de $10-70 \%$. $\mathrm{Na}$ Europa a doença se difundiu no Século XIX, sendo logo erradicada. No ano de 1999 ocorreram surtos em alguns paises do continente, mas atualmente a doença está controlada (OIE 2008). Em condições naturais a CBPP afeta somente ruminantes do gênero Bos, entretanto, a cepa MmmSC, biotipo bovino, tenha sido notificada em búfalos (Bubalus bubalus) na Itália (Santini et al. 1992), bem como em ovinos e caprinos na África, Portugal e Índia (Srivastava et al. 2000). Em se tratando da CCPP, causada pela espécie M. capricolum subsp. capripneumoniae (Mccp), sabe-se que a situação epidemiológica da doença é incerta, devido as dificuldades de isolamento e tipificação do agente, uma vez que a doença pode ser confundida com outras infecções respiratórias (OIE 2008). Ambas as doenças, CBPP e CCPP, pertencem à lista de notificação obrigatória da OIE, e são uma constante preocupação na produção de ruminantes. As outras espécies do GMM, Mcc, MmmLC e Mmc acometem caprinos e ovinos, causando mastite, artrite e conjuntivite em animais adultos. Em cordeiros e cabritos, estas espécies causam principalmente artrite, pleuropneumonia e septicemia, a Síndrome MAKePS (Egwu et al. 1996). Em relação à espécie Msp7 (PG50) está relacionada a surtos de mastites, artrites e abortos em rebanhos caprinos leiteiros na Austrália (Gil et al. 1999).

O Brasil é considerado livre da CBPP e da CCPP, no entanto membros do GMM, já foram diagnosticados no País, tanto por isolamento quanto por técnicas moleculares e sorológicas (Nascimento et al. 1986, Ribeiro et al. 1995, Pereira et al. 2003). Em Nova Friburgo-RJ, Pereira et al. (2003) detectaram DNA de M. mycoides mycoides SC em uma amostra de lavado de conduto auditivo de caprinos assintomáticos para Micoplasmosee. Outras espécies do GMM também tipificadas no País foram $M$. mycoides mycoides LC (antigo agente da CCPP) e M. capricolum, em lavados de conduto auditivo de bovinos assintomáticos (Santos et al. 2009). As espécies M. mycoides mycoides LC e M. mycoides subsp. capri já tinham sido relatadas em surtos de micoplasmose em caprinos no Brasil (Nascimento et al. 1986). Embora sejam alvos de numerosos estudos pela comunidade científica, micoplasmas do GMM ainda não tem uma taxonomia bem estabelecida. Isto se deve em parte à falta de consenso entre pesquisadores, causada principalmente pelo amplo repertório de cepas que circulam em diferentes regiões. Esta dificuldade taxonômica também é atribuída às variações nas propriedades bioquímicas, sorológicas e morfológica das colônias, na especificidade ao hospedeiro e patogenicidade dos membros do GMM (Costas et al. 1987, Weisburg et al. 1989, Razin et al. 1998). Tendo em vista a importância econômico-sanitária da CBPP e a presença de membros do GMM em pequenos ruminantes no Brasil, objetivou-se neste trabalho caracterizar membros deste grupo em cultivos de lavados de conduto auditivo externo de bovinos, tipificando-os pelas técnicas de imunoperoxidase indireta (IPI) e PCR-REA.

\section{MATERIAL E MÉTODOS}

Animais, amostras e região geográfica. No período de março a abril de 2006 foram realizadas lavagens em 60 condutos auditivos de bovinos de abate, animais escolhidos 
de forma aleatória, de ambos os sexos, com idades e raças variadas, procedentes de vários municípios localizados na região sudeste do Estado do Rio de Janeiro, Brasil. Esta Região é caracterizada por clima tropical úmido com precipitação anual de $1200 \mathrm{~mm}^{3}$, com umidades relativas do ar variando de 70 $90 \%$, temperaturas de $24-30^{\circ} \mathrm{C}$ e altitudes de $26-407 \mathrm{~m}$. É caracterizada pela exploração agrosilvopastoril, com destaque para a pecuária de corte, predominando raças zebuínas.

Para a lavagem dos condutos auditivos utilizou-se uma solução salina tamponada (PBS, pH 7,2) disposta em seringas estéreis de $60 \mathrm{ml}$ com sonda plástica $(10 \mathrm{~cm})$ acoplada. Após a coleta, as amostras foram transportadas em caixa isotérmica com gelo para o laboratório, onde foram armazenadas em glicerol (1:2) e congeladas a $-20^{\circ} \mathrm{C}$ até uso. Para o isolamento de Mycoplasma spp., as amostras foram diluídas até $10^{-5}$, sendo então repicadas em meio Hayflick modificado liquido e sólido (Whitford et al. 1994). As placas foram incubadas a $37^{\circ} \mathrm{C}$ por $72-96$ horas em dessecador sob microaerofilia e examinadas diariamente para visualização de colônias típicas em "ovo-frito" sob microscópio estereoscópico (40x). A confirmação de Mycoplasma spp. nas amostras baseou-se nas provas de Dienes, digitonina, fermentação de glicose e hidrólise de arginina (Whitford et al. 1994). As colônias obtidas foram clonadas de acordo com Whitford et al. (1994) e tipificadas pela técnica de IPI segundo Imada et al. (1987). Cepas padrão de membros do GMM pertencentes à coleção Prof. Elmiro R. do Nascimento (Universidade Federal Fluminense, Niterói-RJ), foram utilizadas como controle positivo nas reações de IPI e PCR-REA (Quadro 1).

Quadro 1. Relação das amostras padrão do Grupo Mycoplasma mycoides utilizadas na padronização das reações de PCR

\begin{tabular}{|c|c|c|c|}
\hline Espécie & Cepa & Hospedeiro & Origem \\
\hline $\begin{array}{l}\text { M. mycoides } \\
\text { mycoides LC }\end{array}$ & Y-goat & Caprino/ovino & Europa \\
\hline $\begin{array}{l}\text { M. mycoides } \\
\text { mycoides SC }\end{array}$ & PG1 & Bovino & Europa \\
\hline $\begin{array}{l}\text { M. mycoides } \\
\text { mycoides LC }\end{array}$ & GM12 & Caprino/ovino & USA \\
\hline $\begin{array}{l}\text { M. capricolum } \\
\text { Subsp. capricolum }\end{array}$ & California Kid & Caprino/ovino & USA \\
\hline $\begin{array}{l}\text { M. mycoides } \\
\text { Subsp. capri }\end{array}$ & PG3 & Caprino/ovino & Europa \\
\hline
\end{tabular}

Processamento de amostras para PCR-REA . Para extração de DNA utilizou-se $1 \mathrm{~mL}$ de cultivo de Mycoplasma que foi centrifugado a $13.500 \mathrm{rpm}$ por $20 \mathrm{~min}$ a $4^{\circ} \mathrm{C}$. Um volume de $40 \mu \mathrm{L}$ do sedimento foi resuspenso em $460 \mu \mathrm{L}$ de tampão de lise $(400 \mu \mathrm{L}$ de TE-dextrose [pH 8,4], 30 $\mathrm{LL}$ proteinase $\mathrm{K}[240 \mu \mathrm{g} /$ $\mathrm{mL}$ ], $30 \mu \mathrm{L}$ de SDS a $10 \%$ ), com posterior incubação por 30min a $55^{\circ} \mathrm{C}$ e banho de gelo por cinco minutos. O DNA foi extraído pelo método fenol:clorofórmio:álcool isoamílico em partes iguais (Sambrook et al. 1989), sendo então (re)suspenso em álcool etílico [PA] e mantido $-20^{\circ} \mathrm{C}$ overnight. Os pellets foram obtidos após centrifugação a $13.500 \mathrm{rpm}$ por 20 minutos a $4^{\circ} \mathrm{C}$, em seguida foram mantidos em $100 \mu \mathrm{L}$ de tampão TE (10mM Tris$\mathrm{HCl}, 1 \mathrm{mM}$ EDTA, pH 8.0). Para reação de amplificação do DNA foram utilizados primers específicos para o $\mathrm{GMM}$, os quais amplificam os segmentos $r m A$ e $r m B$ operons do gene 16SrRNA, com os primers F-REAP (5'-GAAACGAAAGATAATA CCGCATGTAG-3') e R-REAP (5'-CCACTTGTGCGGGTCC
CCGTC-3') (Pettersson et al. 1996a, Persson et al. 1999). A reação da PCR constou de $\mathrm{KCL} 50 \mathrm{mM}, \mathrm{MgCL}_{2} 4 \mathrm{mM}$, Tris-HCL 10mM pH 8,3; dNTPmix 0,8mM, 5pmol de cada primer, 0,5U de AmpliTaq, $15 \mu \mathrm{L}$ do DNA extraído e $57 \mu \mathrm{L}$ de água de PCR, totalizando um volume de $100 \mu \mathrm{L}$. Para controle negativo nas reações foi utilizado água de $\mathrm{PCR}$, em substituição ao DNA. A amplificação foi realizada em 33 ciclos de desnaturação a $96^{\circ} \mathrm{C}$ por 30 seg, anelamento a $60^{\circ} \mathrm{C}$ por 30 seg e extensão a $72^{\circ} \mathrm{C}$ por $1 \mathrm{~min}$. A reação foi pré-aquecida a $96^{\circ} \mathrm{C}$ por $3 \mathrm{~min}$ com extensão final a $72^{\circ} \mathrm{C}$ por $5 \mathrm{~min}$. Para diferençar $M$. mycoides mycoides SC de outros membros do GMM o produto da PCR foi digerido com enzima de restrição Alul (Fermentas Life Science, São Paulo$\mathrm{SP}$ ) de acordo com protocolo do fabricante. A reação em volume final de $20 \mu \mathrm{L}$ constou de $1 \mathrm{x}$ tampão Tango (Tris-acetato $33 \mathrm{mM}$ pH 7.9, acetato de magnésio $10 \mathrm{mM}$, acetato de potássio $66 \mathrm{mM}$, BSA 0,1 g/mL, DTT 1mM, glicerol 50\%), $5 U$ de enzima. A digestão foi realizada a $37^{\circ} \mathrm{C}$ por duas horas com inativação a $65^{\circ} \mathrm{C}$ por $20 \mathrm{~min}$. As amostras foram analisadas em gel de agarose a $3,2 \%$ corado em brometo de etídio (5\%) e os fragmentos obtidos foram visualizados sob luz ultravioleta. Foi utilizado o marcador de peso molecular 100pb (Ladder ${ }^{\circledR}$, Rio Grande do Sul).

Análise estatística. Para análise de concordância entre os resultados obtidos na IPI e PCR-REA foi utilizado o teste Kappa (Pereira 2003).

\section{RESULTADOS \\ Isolamento e identificação}

Dos 60 condutos auditivos de bovinos pesquisados, Mycoplasma spp. foram isolados em $48(80,00 \%)$, destes 35 $(72,92 \%)$ produziram características bioquímicas e fisiológicas indicativas do GMM. Na tipificação pela IPI obteve-se uma prevalência para o GMM de 20,0\% (12/60), enquanto que pela PCR-REA a prevalência foi de $41,7 \%$ (25/60). Dos 12 isolados tipificados pela IPI 58,3\% (7/12) tiveram reação positiva intensa para a espécie MmmLC (Y-goat) (Fig.1) e $41,7 \%$ (5/12) para M. capricolum. No teste Kappa a concordância entre IPI e PCR foi considerada fraca, indicando não haver associação significativa entre as técnicas $(K=0,14$, $p>0,05$ ) (Quadro 2). Na PCR dos cultivos de lavados de ouvido de bovinos, foi possível visualizar uma banda específica

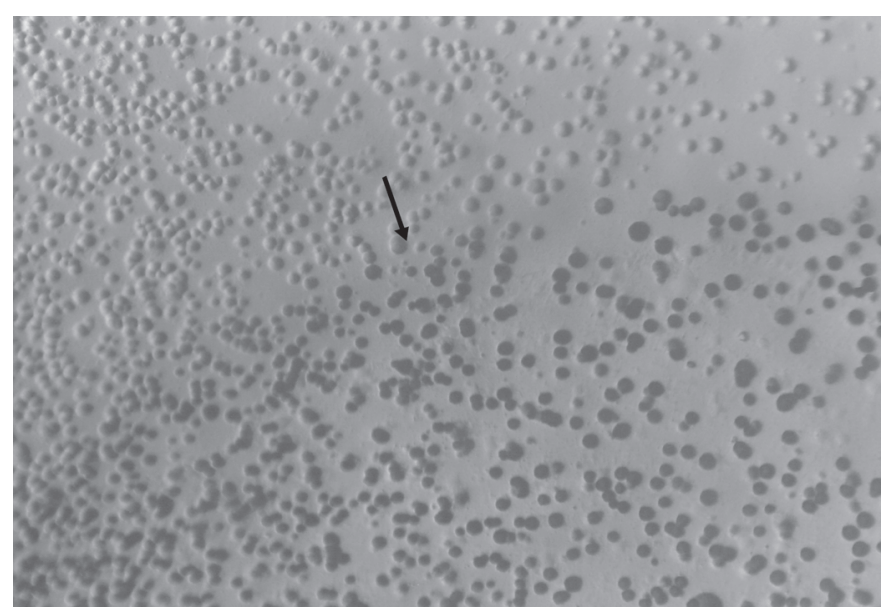

Fig.1. Colônias de M. mycoides mycoides LC (MmmLC), isoladas de conduto auditivo de bovinos, positivas na imunoperoxidase indireta. 
Quadro 2. Isolados do Grupo Mycoplasma mycoides detectados por imunoperoxidase indireta (IPI) e PCR-REA em conduto auditivo de bovinos do Estado do Rio de Janeiro

\begin{tabular}{cccc}
\hline Diagnóstico para & \multicolumn{2}{c}{ PCR-REA } & Total \\
\cline { 2 - 3 } Grupo GMM por (IPI) & Positivo & Negativo & \\
\hline Positivo & 10 & 2 & 12 \\
Negativo & 15 & 8 & 23 \\
Total & 25 & 10 & 35
\end{tabular}
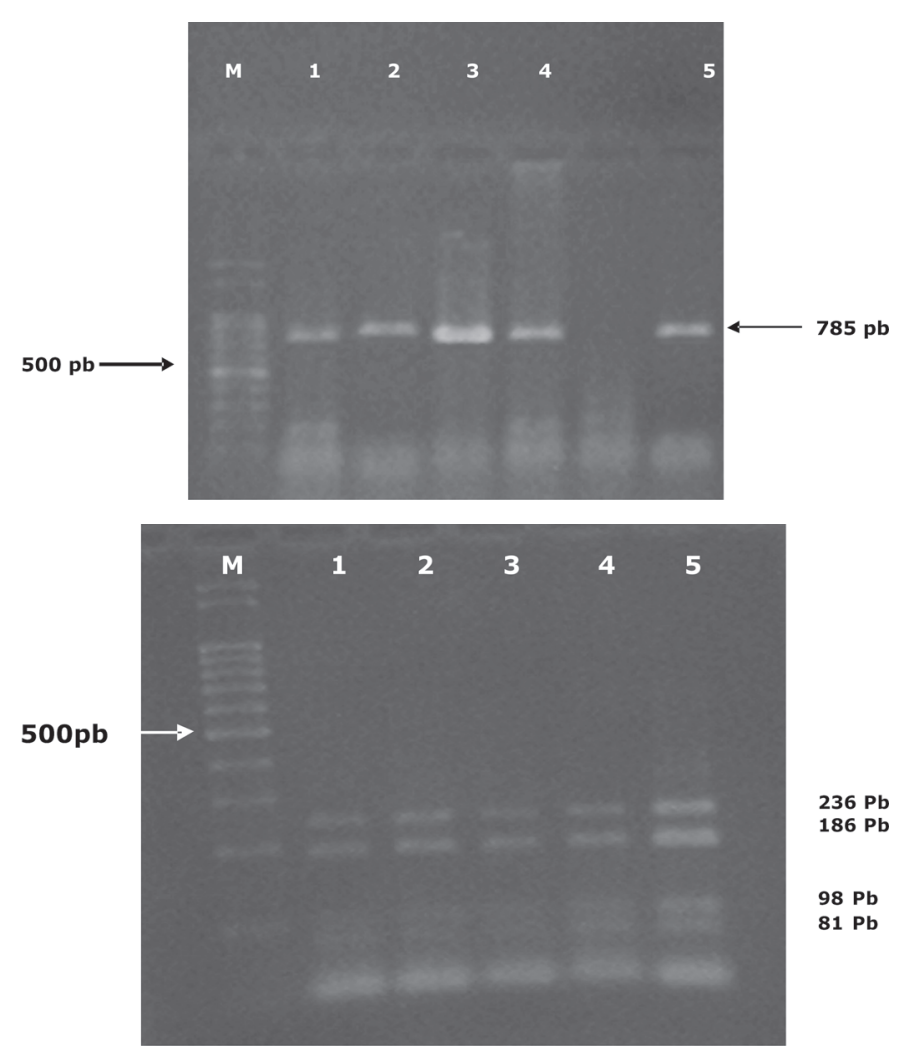

Fig.2. (A) PCR positiva para Mycoplasma mycoides nos isolados de ouvido de bovinos, Rio de Janeiro, Brasil. M: marcador de peso molecular (Ladder 100®); 1, 2, 4 e 5: M.mycoides subsp. mycoides tipo LC; 3: M.capricolum subsp. Capricolum). (B) Resultados dos amplicons obtidos para o Grupo Mycoplasma mycoides após digestão com enzima de restrição de endonuclease com Alul. M: Ladder100pb; 1 5: amostras de lavados de conduto auditivo de bovinos.

de 785pb, compatível com o GMM (Fig.2A e 2B), o mesmo foi verificado nas cepas de referência utilizadas como controle positivo. Na clivagem dos amplicons de 785pb das cepas de referências e dos isolados de ouvido, foram visualizadas em gel de agarose, fragmentos com os tamanhos de 81, 98, 186 e 236pb. Nos isolados de ouvido de bovinos nenhum fragmento com tamanho de 370pb, compatível com MmmSC, foi detectado, sendo este fragmento observado apenas na cepa MmmSC (PG1) utilizada como controle positivo.

\section{DISCUSSÃO}

A prevalência de Mycoplasma spp. no conduto auditivo de bovinos foi elevada, indicando que o agente encontra-se amplamente difundido na área estudada. Os resultados encontrados para PCR-REA e IPI em lavados de ouvido de bovinos, no Brasil, demonstram que neste sítio são encontradas várias espécies de micoplasmas com possível potencial patogênico e que bovinos assintomáticos albergam cepas do GMM. Destacou-se neste estudo a presença das cepas $M$. mycoides mycoides LC e M. capricolum, espécies encontradas em caprinos e ovinos que podem eventualmente serem isoladas de bovinos (OIE 2008). Mycoplasmas spp. em conduto auditivo de bovinos podem ocorrer como saprófitas (Whitcomb \& Bové 1983, Barber et al. 1986, Woldehiwet et al. 1990) ou como patogênicos em surtos de micoplasmoses (Adegboye et al. 1995, Rodríguez et al. 1996, Alberti et al. 2006). Os animais utilizados nesta pesquisa foram procedentes de uma região de exploração extensiva de bovinos de corte, onde, possivelmente, a coabitação de bovinos com caprinos e/ ou ovinos pode ter contribuído para a circulação de cepas do GMM entre estes animais.

Quanto a técnica empregada observou-se que a PCRREA detectou cerca do dobro das tipificações pela IPI, o que indica uma maior sensibilidade da PCR em relação à IPI. Além disso, a PCR-REA é considerada específica para detectar este grupo em amostras de campo, contudo, a PCR-REA não se presta à diferenciação de subespécies do grupo, exceto a cepa $M m m S C$, sendo um método de escolha para o diagnóstico da CBPP e triagem do GMM, em áreas com suspeita. Estes achados estão de acordo com estudos prévios de Pettersson et al. (1996a) e Le Grand et al. (2004), que relataram problemas para separar cepas do GMM, uma vez que as espécies $M m m L C, M m c$, Mcc, Mccp e Msp7 apresentam um mesmo padrão de bandas na PCR-REA, não sendo possível distingui-las. Contudo a espécie $\mathrm{MmmSC}$ quando submetida à análise por PCR-REA apresenta uma banda extra de 370 pb que a diferencia das demais do GMM, devido a um polimorfismo na posição 426 do gene 16 SrRNA. A PCR-REA tem sido relatada como uma técnica muito específica para o GMM, não amplificando outras espécies comuns a bovinos, como M. bovigenitalium, M. bovirhinis, $M$. bovis, $M$. bovoculi e M. canis (Le Grand et al. 2004). Persson et al. (1999a) ressaltaram que a detecção de M.mycoides SC após restrição de amplicons possui uma sensibilidade técnica estimada em 30 cópias de DNA por reação de amplificação. Em se tratando de tipificação de cepas do GMM pela técnica de IPI, são freqüentes a presença de reações cruzadas entre as subespécies, o que dificulta a caracterização, embora esta possa ser utilizada como ferramenta para tipificação diagnóstica para triagem, necessitando de uma caracterização molecular complementar. Quando não se dispõe da ferramenta molecular para diagnóstico laboratorial, a IPI pode ser utilizada na separação dos dois principais subgrupos do GMM (Mycoides e Capricolum). A dificuldade em tipificar isolados de campo é freqüente devido às semelhanças antigênicas das cepas e também pela presença de cepas intermediárias entre alguns sorotipos ou sorogrupos. Isto se deve principalmente a sua 
alta plasticidade genotípica (Dybvig \& Voelker 1996, Rottem 2003, Razin et al. 2008), assim com frequencia estas cepas podem se adaptar a diferentes hospedeiros, tornando mais difícil o diagnóstico em amostras de campo em animais assintomáticos.

Agradecimentos.- Ao Conselho Nacional de Desenvolvimento Científico e Tecnológico (CNPq) pela concessão de Bolsa durante o desenvolvimento da pesquisa.

\section{REFERÊNCIAS}

Adegboye D.S., Halbur P.G., Cavanaugh D.L., Werdin R.E., Chase C.C.L., Miskimins D.W. \& Rosenbusch R.F. 1995. Immunohistochemical and pathological study of Mycoplasma bovis-associated lung abscesses in calves. J. Vet. Diagn. Invest. 7:333-337.

Alberti A., Addis M.F., Chessa B., Cubeddu T., Profiti M., Rosati S., Ruiu A. \& Pittau M. 2006. Molecular and genetic characterization of a Mycoplasma bovis strain causing an outbreak of infectious keratoconjunctivitis. J. Vet. Diagn. Invest. 18:41-51.

Barber D.M., Jones G.E. \& Wood A. 1986. Microbial flora of the eye of cattle. Vet. Rec. 118: 204-206.

Costas M., Leach R.H. \& Mitchelmore D.L. 1987. Numerical analysis of PAGE protein patters and the taxonomic relation within the "Mycoplasma mycoides Cluster". J. Gen. Microbiol. 133:3319-3329.

Dybvig K. \& Voelker L.L. 1996. Molecular biology of mycoplamas. Ann. Rev. Microbiol. 50:25-57.

Egwu G.O., Nicholas R.A.J., Ameh J.A. \& Bashiruddin J.B. 1996. Contagious bovine pleuropneumonia: An update. Vet. Bull. 66:875888.

Gil M.C., Mendoza M.H., Rey J., Alonso J.M., Poveda J.B. \& Mendoza J.H. 1999. Isolation of mycoplasmas from the external ear canal of goats affected with contagious agalactia. Vet. J. 158:152-154.

Imada Y., Uchida I. \& Hashimoto K. 1987. Rapid identification of Mycoplasma by indirect immunoperoxidase test using small square filter paper. J. Clin. Microbiol. 25:17-21.

Le Grand D., Saras E., Blond D., Solsona M. \& Poumarat F. 2004. Assessment of PCR for routine of the Mycoplasma mycoides Cluster in ruminants. Vet. Res. 35:635-649.

Nascimento E.R., Nascimento M.G.F., Freund E.A. \& Andersen H.1986. Isolation of Mycoplasma mycoides from outbreaks of caprine mycoplasmosis in Brazil. Brit. Vet. J. 142:246-257.

OIE 2008. Terrestrial Manual, Contagious Bovine Pleuropneumonia, Organização Internacional de Epizootias, p.712-724. <www.oie.int.>

Pereira M.G. 2003. Epidemiologia Teoria e Prática. Guanabara Koogan, Rio de Janeiro, 596p.

Pereira L.O., Danelli M.G.M., Mazur C. \& Galler R. 2003. Identificação molecular de Mycoplasma mycoides subesp. mycoides SC isolado do conduto auditivo externo de caprinos clinicamente saudáveis. Ciência Rural 33:367-368.

Persson A., Pettersson B., Bolske G. \& Johansson K.E. 1999. Diagnosis of contagious Bovine Pleuropneumonia by PCR-lazer-induced fluorescence and PCR-restriction endonuclease analysis based on the 16SrRNA genes of Mycoplasma mycoides subsp. mycoides SC. J. Clin. Microbiol. 37:3815-3821.

Pettersson B., Leitner T., Ronaghi M., Bolske G., Uhlén M. \& Johansson K.E. 1996a. Phylogeny of the Mycoplasma mycoides Cluster as determined by sequence analysis of the 16SrRNA genes from the two rRNA operons. J. Bacteriol. 178:4131-4142.

Pettersson B., Uhlén M. \& Johansson K.E. 1996b. Phylogeny of some mycoplasmas from ruminants based on 16SrRNA sequence and definition of a new Cluster within the Hominis Group. Int. J. Syst. Evol. Microbiol. 46:1093-1098.

Razin S., Yogev D. \& Naot Y. 1998. Molecular biology and pathogenicity of mycoplasmas. Microbiol. Mol. Biol. Rev. 62:1094-1156.

Ribeiro V.R., Nascimento E.R., Faccini J.L.H., Nascimento M.G.F. \& Lignon G.B. 1995. Ocorrência de micoplasmas em caprinos através das técnicas de imunofluorescência direta e inibição do crescimento. Revta Brasil. Med. Vet. 17:26-28.

Rodríguez F., Bryson D.G., Ball H.J. \& Forster F. 1996. Pathological and immunohistochemical studies of natural and experimental Mycoplasma bovis pneumonia in calves. J. Comp. Pathol. 115:151162.

Rottem S. 2003. Interactions of mycoplasmas with host cells. Physiol. Rev. 83:417-432.

Sambrook J., Fritsh E.F. \& Maniatis T. 1989. Molecular Cloning Laboratory Manual. Cold Spring Harbor Laboratory Press, Cold Spring Harbor, NY. 523p.

Santini F.G., Visaggio M., Farinellli G., Di Francesco G., Guarducci M., D'Angelo A.R., Scacchia M. \& Di Giannatae E. 1992. Pulmonary sequestrum from Mycoplasma mycoides var. mycoides SC in a domestic buffalo: Isolation, anatomo-histopathology and immunohistochemistry. Vet. Ital. 4:4-10.

Santos S.B., Nascimento E.R., Faccini J.L.H., Barreto M.L. \& Pereira V.L.A. 2009. Patogenic mycoplasmas in the external ear canal of clinically normal cattle in southeast Brazil: First report. Braz. J. Microbiol. 40:455-457.

Srivastava N.C., Thiaucourt F., Singh V.P., Sunder J. \& Singh V.P. 2000. Isolation of Mycoplasma mycoides small colony type from contagious caprine pleuropneumonia in India. Vet. Rec. 147:520521.

Weisburg W.G., Tully J.G., Rose D.L., Petzel J.P., Oyaizu, Yang D., Mandelco L., Sechrest J., Lawrence T.G., Van Etten J., Maniloff J. \& Woese C.R. 1989. A phylogenetic analysis of the micoplasmas: Basis for their classification. J. Bacteriol. 171:6455-6467.

Whitford H.W., Rosenbusch R.F. \& Lauerman L.H. 1994. Mycoplasmosis in Animals: Laboratory diagnosis. lowa State University Press, Ames. 173p.

Whitcomb R.F. \& Bové J.M. 1983. Mycoplasma-plant-insect interrelationships, p.21-25. In: Razin S. \& Tully J.G. (Eds), Methods in Mycoplasmology. Vol.1. Academic Press, New York. 504p.

Woldehiwet Z., Mamache B. \& Rowan T.G. 1990. Effects of age, environmental temperature and relative humidity on the colonization of the nose and trachea of calves by Mycoplasma spp. Brit. Vet. J. $146: 419-424$ 